\title{
Level of adherence to dietary recommendations and barriers among type 2 diabetic patients: a cross-sectional study in an Ethiopian hospital
}

Asnakew Achaw Ayele ${ }^{1 *} \mathbb{D}$, Yohannes Kelifa Emiru², Sofonyas Abebaw Tiruneh ${ }^{3}$, Belete Achamyelew Ayele ${ }^{4}$, Alemayehu Digssie Gebremariam ${ }^{3}$ and Henok Getachew Tegegn ${ }^{1,5}$

\begin{abstract}
Background: Limited data are available regarding the level of adherence and barriers to dietary recommendations in individuals with type 2 diabetes in Africa including Ethiopia. Therefore, this study aimed at assessing the level of dietary adherence and its barriers among patients with type 2 diabetes in northwest Ethiopia.

Methods: A prospective hospital-based cross-sectional study was conducted from August to October 2017 at Debre Tabor General Hospital, Northwest Ethiopia. The Perceived Dietary Adherence Questionnaire (PDAQ) was used for dietary adherence measurement. Multivariate logistic regression was done to identify the barriers influencing dietary adherence.

Result: A significant percentage (74.3\%) of the study participants had poor adherence to dietary recommendations. The highest mean score was obtained for the question regarding consuming foods high in sugar with a mean $5.49 \pm$ 1.20 times a week. On the other hand, our participants had a low consumption of fruits and vegetables and foods high in omega-3 fats with a mean of $1.84 \pm 1.96$ and $0.1 \pm 0.62$ times a week respectively. According to the survey of participants, lack of knowledge, lack of diet education, inability to afford the cost of healthy diet and poor awareness about the benefit of dietary recommendations were the most cited reasons for poor dietary adherence. In multivariate logistics regression, low level of educational status, the presence of co-morbidities, lack of previous exposure to dietary education and low monthly income were statistically significant factors associated with non-adherence.
\end{abstract}

Conclusion: The rate of non-adherence to dietary recommendation among patients with T2DM was found to be high in northwest Ethiopia. Hence, providing customized health education about the potential benefit of proper dietary recommendations in controlling blood glucose is recommended. Health care providers should be proactive in promoting adherence to dietary recommendations in patients with T2DM.

Keywords: Type 2 diabetes, Diabetic, Dietary recommendations, Adherence, Ethiopia

\section{Introduction}

According to the latest data from the World Health Organization (WHO), an estimated 422 million adults are living with diabetes mellitus (DM) worldwide [1]. In 2013, the International Diabetes Federation (IDF) estimated that 381 million people having diabetes [2]. This figure is expected to be almost double by 2030. Diabetes

\footnotetext{
* Correspondence: asnake.21.uog@gmail.com

'Department of Clinical Pharmacy, School of Pharmacy, College of Medicine and Health Science, University of Gondar, BOX 520 Gondar, PO, Ethiopia Full list of author information is available at the end of the article
}

mellitus occurs throughout the world, but it is more common; especially type 2 diabetes (T2DM) in more developed countries. However, there is the greatest increase in prevalence in low- and middle-income countries where most patients will probably be from by 2030. This increasing incidence in developing countries follows the trend of urbanization and lifestyle changes, including increasingly sedentary lifestyles, less physically demanding work and the global nutrition transition, marked by increased intake of foods that are energydense but nutrient-poor. International Diabetes Fund

(C) The Author(s). 2018 Open Access This article is distributed under the terms of the Creative Commons Attribution 4.0 International License (http://creativecommons.org/licenses/by/4.0/), which permits unrestricted use, distribution, and 
estimates that 14.2 million are living with diabetes in the African region [3]. To prevent type 2 diabetes and its complications, WHO recommends that patients achieve and maintain a healthy body weight, perform a regular physical activity for at least $30 \mathrm{~min}$ and moderate-intensity activity on most days, eat a healthy diet, and avoid sugar and saturated fats intake and tobacco use [3]. A healthy diet helps protect against malnutrition in all its forms, as well as non-communicable diseases (NCDs), including diabetes, heart disease, stroke, and cancer [4]. The American Diabetes Association (ADA) recommends that eating fruits, vegetables, whole grains, legumes, fiber-containing foods and minimizing highly sucrose-containing foods are beneficial for secondary prevention of T2DM [5]. Failure to implement such approaches will force intensification of pharmacologic treatments or result in suboptimal glycemic control. Although dietary modification has been anticipated as the keystone of T2DM management and is usually recommended as the first step, it is considered one of the most challenging aspects of diabetes management. Regular implementation of recommended dietary practice for individuals with T2DM requires collaboration between the patient and the healthcare provider. Dietary non-adherence in people with T2DM has been identified as high in both developed and developing countries [6-8]. Factors identified as reasons for poor adherence to dietary recommendations are socioeconomic status, duration of disease, lack of diabetes knowledge, cost of healthy diet and poor communication with healthcare providers are among the most cited barriers in most of the existing data [9-12]. There is, however, limited data regarding the level of adherence and barriers to dietary recommendations in individuals with T2DM in Africa including Ethiopia. A few reports in Ethiopia and other parts of Africa suggests that patients with diabetes adherence to the dietary recommendation is generally low [13-16]. In Ethiopia, there is no dietary practice guideline and there is lack of information on the proper dietary practice for people with T2DM. Moreover, because of the paucity of evidence-based research, the health policy of Ethiopia, is still unable to give attention to this topic. Conducting and documenting such research would have a positive impact on designing and implementation of dietary practice programs for people with T2DM in Ethiopia. Therefore, this study aimed at assessing the level of dietary adherence and its barriers to dietary recommendations among people with T2DM with the representation of Northwest Ethiopia.

\section{Methods and settings}

A prospective hospital-based cross-sectional study was conducted from August to October 2017 at Debre Tabor General Hospital, northwest Ethiopia. The hospital is located in Debre Tabor town, northwest Ethiopia which is $667 \mathrm{~km}$ away from the capital, Addis Ababa. The hospital is equipped with 91 beds for inpatient services and different outpatient departments including chronic illness clinics.

\section{Patients' recruitment}

All patients with T2DM aged $>18$ years who visited the hospital for follow-up from August 1-October 30-2017 were invited to participate in the study. On the other hand, those who were critically ill and unable to participate in the interview and also those who were recently diagnosed and had a follow-up of fewer than 6 months were excluded.

\section{Ethical considerations}

Ethical approval was obtained from the ethical review board of Debre Tabor University. Informed verbal consent was also obtained from each respondent after explaining the purpose of the study. Participant's confidentiality was guaranteed by not recording their personal identifiers on the data collection format.

\section{Data quality control technique}

Data collectors were trained intensively on the contents of the questionnaire, data collection methods, and ethical concerns. The questionnaires were translated into Amharic (local language) so as to maintain the unbiased response. The filled questionnaires were checked daily for completeness by the principal investigator. The reliability (psychometric property) of the tool was evaluated and demonstrated a Cronbach alpha value of 0.871 . The content of the questionnaires was reviewed by senior experts of nutrition, medical doctors and clinical pharmacists.

\section{Data collection tool and method}

The data collection tool used in this study was adopted and modified from previous studies on similar topics. The questionnaire has two major parts. Part one assessed the sociodemographic characteristics of respondents. Part two included queries about dietary adherence. The Perceived Dietary Adherence Questionnaire (PDAQ) was used for dietary adherence measurement. PDAQ is nine-item questioners which is developed in 2015 by Ghada Asaad et al. to measure patient perceptions of their dietary adherence [17]. The response is based on a seven-point Likert scale to answer the question phrased as "On how many of the last 7 days did you ....?" (Table 1). Higher scores reflect higher adherence except for items 4 and 9, which reflect unhealthy choices (foods high in sugar or fat). For these items, higher scores reflect lower adherence, therefore, for computing a total PDAQ score, the scores for these items were inverted. Patients were classified as having good dietary adherence if they eat a healthy diet for at leaset four days in the week. 
Table 1 Perceived Dietary Adherence Questionnaire (PDAQ) score for DM patients

\begin{tabular}{|c|c|}
\hline Item & mean, SD \\
\hline On how many of the last SEVEN DAYS have you followed a healthful eating plan? & $4.9 \pm 0.91$ \\
\hline On how many of the last SEVEN DAYS did you eat the number of fruit and vegetables? & $1.84 \pm 1.96$ \\
\hline $\begin{array}{l}\text { On how many of the last SEVEN DAYS did you eat carbohydrate-containing foods with a low Glycemic Index? (Example: dried } \\
\text { beans, lentils, barley, pasta, low fat dairy products) }\end{array}$ & $5.21 \pm 1.95$ \\
\hline On how many of the last SEVEN DAYS did you eat foods high in sugar, such as rice, potatoes, etc.? & $5.49 \pm 1.20$ \\
\hline On how many of the last SEVEN DAYS did you eat foods high in fiber such as oatmeal, high fiber cereals, and whole-grain breads? & $4.01 \pm 1.95$ \\
\hline On how many of the last SEVEN DAYS did you space carbohydrates evenly throughout the day? & $1.67 \pm 2.01$ \\
\hline On how many of the last SEVEN DAYS did you eat fish or other foods high in omega-3 fats? & $0.1 \pm 0.62$ \\
\hline On how many of the last SEVEN DAYS did you eat foods that contained or was prepared with canola, walnut, olive, or flax oils? & $4.30 \pm 3.24$ \\
\hline $\begin{array}{l}\text { On how many of the last SEVEN DAYS did you eat foods high in fat (such as high fat dairy products, fatty meat, fried foods or } \\
\text { deep-fried foods)? }\end{array}$ & $4.61 \pm 1.61$ \\
\hline \multicolumn{2}{|l|}{ Over all adherence - $(n, \%)$} \\
\hline Poor & $238(74.3)$ \\
\hline Good & $82(25.7)$ \\
\hline
\end{tabular}

\section{Data entry and analysis}

The collected data was cleaned and entered to analyze using IBM SPSS Statistics for Windows, version 20.0. Descriptive statistics (percentage, mean and standard deviation) was used to present categorical data. Multivariate logistic regression was conducted to determine the barriers influencing dietary adherence. The results were considered to be statistically significant where $p$-value was $<0.05$.

\section{Results}

Table 2 shows the socio-demographic characteristics of participants. The mean age of the participants was 52.7 and more than half of them were males. About $43.1 \%$ of the participants had no education and only $17.8 \%$ of the participants had higher education. More than half of the study participants had had total monthly incomes of less than $\$ 250$ and about $59.4 \%$ of them were living in a rural area. The mean duration since diagnosis of DM and duration since starting DM treatment among the study participants were 5.3 and 5.2 years respectively. About $28.1 \%$ of the participants had a family history of DM and the prevalence of comorbidities was $40.3 \%$. A significant percentage (52.8\%) of the study participants had not received education about dietary recommendation and $63.8 \%$ of the total DM patients were unable to follow doctor's recommendation regarding diet while large number $(84 \%)$ of the participants had a problem of remembering eating foods according to doctor's advice. Additional details of the study participants are found in Table 2.

Perceived dietary adherence questionnaire (PDAQ) score The mean scores of each item of PDAQ are shown in Table 3. The highest mean score was obtained for the question 'On how many of the last SEVEN DAYS did you eat foods high in sugar, such as rice, potatoes, etc.?'
The second highest mean score was obtained for the question 'On how many of the last SEVEN DAYS have you followed a healthful eating plan?' participants obtained the lowest mean score, for the question 'On how many of the last SEVEN DAYS did you eat fish or other foods high in omega-3 fats?' and On how many of the last SEVEN DAYS did you eat the number of fruit and vegetables?. A significant percentage (74.3\%) of the study participants had poor adherence based on PDAQ while only $25.7 \%$ of the participants had good adherence towards dietary recommendations.

\section{Perceived barberries influencing adherence to the recommended diet}

A large number of study participants (87\%) cited lack of knowledge/lack of diet education as the main barriers that hinder adherence to recommended diets. In addition to this, $78 \%$ of the participant reported that they were unable to afford the cost of the recommended diet as the reason for non-adherence. Moreover, $67 \%$ of the participants did not believe that a diet could control blood glucose. The difficulty of remembering recommended diet was cited as a reason for non-adherence by $57 \%$ of the study participants. The participants were asked whether social or work events influence their adherence to dietary recommendations and $39 \%$ of them reported that as a reason. Stress was another important barrier which was cited by $46 \%$ of the participants. In Multivariate logistic regression analysis, respondents who had no formal education were 2.6 times more likely to have poor adherence to dietary recommendations than those who had a higher education $(\mathrm{AOR}=2.613$ (95\%CI, 2.021, 6.664). Regarding residency, patients who are living in a rural area were 2.4 times less adherence to their dietary recommendations for diabetes $(\mathrm{AOR}=2.423$ (95\%CI 2.132-4.067). Moreover, participants with monthly 
Table 2 Socio-demographic characteristics of the respondent

\begin{tabular}{|c|c|}
\hline Patient characteristics and clinical data & N (\%) \\
\hline Total number of the study population, $\mathrm{N}$ & 320 \\
\hline \multicolumn{2}{|l|}{ Sex } \\
\hline Male, n (\%) & $168(52.5 \%)$ \\
\hline Female- n, (\%) & $152(47.5 \%)$ \\
\hline Age- mean, (SD) & $52.69 \pm 12.29$ \\
\hline \multicolumn{2}{|l|}{ Marital status } \\
\hline Single- $n(\%)$ & $33(10.3 \%)$ \\
\hline Married- n, (\%) & $218(68.1 \%)$ \\
\hline Divorced- n, (\%) & $56(17.5 \%)$ \\
\hline Separated- n, (\%) & $12(3.8 \%)$ \\
\hline \multicolumn{2}{|l|}{ Resident } \\
\hline Urban - n, (\%) & $190(59.4 \%)$ \\
\hline Rural - n, (\%) & $130(40.6 \%)$ \\
\hline \multicolumn{2}{|l|}{ Educational status } \\
\hline Unable to read and write-, n, (\%) & $138(43.1 \%)$ \\
\hline Able to read and write $-, n,(\%)$ & $64(20 \%)$ \\
\hline Primary education-, n, (\%) & $25(7.8 \%)$ \\
\hline Secondary education- n, (\%) & 35 (10.9\%) \\
\hline Higher education- n, (\%) & $57(17.8 \%)$ \\
\hline \multicolumn{2}{|l|}{ Occupational status } \\
\hline Student - n, (\%) & $4(1.25 \%)$ \\
\hline Unemployed - n, (\%) & $82(25.6 \%)$ \\
\hline Government employed- n, (\%) & $78(24.3 \%)$ \\
\hline Self-employed- n, (\%) & $121(37.9 \%)$ \\
\hline Non-governmental employed- n, (\%) & 35 (10.9\%) \\
\hline \multicolumn{2}{|l|}{ Monthly income in USD } \\
\hline$>250-n,(\%)$ & $43(13.4 \%)$ \\
\hline 150-250- n, (\%) & 95 (29.7\%) \\
\hline$<150-\mathrm{n},(\%)$ & $182(56.6 \%)$ \\
\hline Duration since diagnosis of DM - mean, (SD) & $5.31 \pm 3.87$ \\
\hline Duration since starting DM treatment - mean, (SD) & $5.16 \pm 3.77$ \\
\hline \multicolumn{2}{|l|}{ Family history of DM } \\
\hline Yes & $90(28.1 \%)$ \\
\hline No & $230(71.9 \%)$ \\
\hline \multicolumn{2}{|l|}{ Co-morbidity } \\
\hline Yes & $129(40.3 \%)$ \\
\hline No & $191(59.7 \%)$ \\
\hline \multicolumn{2}{|l|}{ Physical exercise } \\
\hline Yes & $122(38.1 \%)$ \\
\hline No & $198(61.9 \%)$ \\
\hline
\end{tabular}

Previous exposure to any education regarding diet recommendation from healthcare providers

Yes

$148(46.2)$

No
Table 2 Socio-demographic characteristics of the respondent (Continued)

\begin{tabular}{ll}
\hline Patient characteristics and clinical data & $N(\%)$ \\
\hline Follow doctor's recommendation regarding diet & \\
Yes & $116(36.2)$ \\
No & $204(63.8)$
\end{tabular}

Encounter problem of remembering eating foods according to doctors advise

Yes 269 (84.0)

No

$51(16.0)$

income below $\$ 150$ were poorly adherent to dietary recommendations (AOR $=6.781,(95 \% \mathrm{CI} 2.001-9.902)$. The presence of co-morbidity was associated with increased non-adherence to dietary recommendations $(\mathrm{AOR}=$ $7.60,95 \% \mathrm{CI}, 3.29,14.845)$. The occurrence of poor-adherence to dietary recommendations was 8.1 times more likely among patients who had not received any education about dietary recommendations from health care providers compared with those who had exposure to dietary education ( $\mathrm{AOR}=8.14,95 \%$ CI,2.27-47.29). However other characteristics (age group and sex) were not significantly associated with non-adherence to dietary recommendations (Table 4).

\section{Discussion}

Our study found that overall adherence levels to dietary recommendations for T2DM were poor among Ethiopian patients with T2DM, with only $25.7 \%$ of study participants following their doctor's recommendation. This non-adherence level was comparable with studies done in other countries globally [18-21]. Another study was done on dietary practice and associated factors in Addis Ababa, Ethiopia has indicated that there was a $51.4 \%$ poor diet adherence [14] which is lower than the finding

Table 3 Perceived Barriers influencing adherence to the recommended diet

\begin{tabular}{lc}
\hline Barriers & $\%$ \\
\hline Lack of knowledge/lack of diet education & 87 \\
Unable to afford Cost of the recommended diet & 78 \\
Don't believe diet can control blood glucose & 67 \\
Lack of Appetite for recommended diet & 17 \\
Unable to remember the recommended diet & 57 \\
It takes too long to cook recommended diet & 21 \\
The difficulty of adhering to the recommended diet during & 39 \\
social or work events & 46 \\
Stress & 12 \\
Other & \\
\hline
\end{tabular}

NB: more than one answer is possible for the above questions 
Table 4 Test of association between predictive variables with level of adherence

\begin{tabular}{|c|c|c|c|c|c|}
\hline \multirow[t]{2}{*}{ Variables } & \multicolumn{2}{|l|}{ Adherence } & \multicolumn{2}{|l|}{ OR $(95 \% \mathrm{Cl})$} & \multirow[t]{2}{*}{ P-value } \\
\hline & Poor (238) & Good (82) & COR & $\mathrm{AOR}$ & \\
\hline \multicolumn{6}{|l|}{ Resident } \\
\hline Urban & 129 & 61 & - & - & - \\
\hline Rural & 109 & 21 & $2.254(2.015-2.922)$ & $2.423(2.132-4.067)$ & $0.043^{*}$ \\
\hline \multicolumn{6}{|l|}{ Educational status } \\
\hline Unable to read and write & 131 & 7 & $2.241(2.041-3.441)$ & $2.613(2.021,6.664) *$ & $0.032^{*}$ \\
\hline Primary education & 16 & 9 & $0.98(0.679-1.226)$ & $0.643(0.0324-1.079)$ & 0.623 \\
\hline Secondary education & 17 & 18 & $0.76(0.214-2.940)$ & $0.482(0.09-4.371)$ & 0.751 \\
\hline Higher education & 57 & 48 & - & - & - \\
\hline \multicolumn{6}{|l|}{ Occupational status } \\
\hline Student & 2 & 2 & - & - & - \\
\hline Unemployed & 70 & 12 & $2.431(2.018,12.790)$ & $4.148(2.641,19.13) *$ & $0.024^{*}$ \\
\hline Government employee & 49 & 29 & $0.769(0.49-2.52)$ & $0.83(0.55,1.98)$ & 0.641 \\
\hline Self-employed & 96 & 25 & $0.62(0.21-2.84)$ & $1.74(0.50,10.66)$ & 0.645 \\
\hline Non-governmental employee & 21 & 14 & $0.869(0.49-2.52)$ & $0.93(0.25,1.87)$ & 0.751 \\
\hline \multicolumn{6}{|l|}{ Monthly income in USD } \\
\hline$>250$ & 5 & 38 & - & - & - \\
\hline $150-250$ & 61 & 34 & $2.322(0.845-5.799)$ & $1.833(0.672-5.513)$ & 0.237 \\
\hline$<150$ & 172 & 10 & $4.860(2.003-9.484)$ & $6.781(2.001-9.902)$ & $0.027^{*}$ \\
\hline \multicolumn{6}{|l|}{ Duration since diagnosis of DM } \\
\hline $0-5$ years & & & - & - & - \\
\hline $5-10$ years & & & $0.0881(0.0764-14.704)$ & $0.076(0.032-19.872)$ & 0.075 \\
\hline$>10$ years & & & $2.434(2.115-8.230)$ & $2.814(2.781-12.060)$ & $0.037^{*}$ \\
\hline \multicolumn{6}{|c|}{ Duration since starting DM treatment } \\
\hline $0-5$ years & & & $3.74(1.415-9.230)$ & $5.714(2.81-14.160)$ & 0.07 \\
\hline $5-10$ years & & & $0.881(0.264-3.704)$ & $2.626(1.103-3.872)$ & 0.065 \\
\hline$>10$ years & & & - & - & - \\
\hline \multicolumn{6}{|l|}{ Family history of DM } \\
\hline Yes & 29 & 61 & - & - & - \\
\hline No & 209 & 21 & $1.054(0.645-1.722)$ & $0.823(0.432-1.567)$ & 0.55 \\
\hline \multicolumn{6}{|l|}{ Co-morbidity } \\
\hline Yes & 108 & 21 & $4.76(2.55,7.03)$ & $7.60(3.29,14.845) *$ & $0.002^{*}$ \\
\hline No & 130 & 61 & - & - & - \\
\hline \multicolumn{6}{|l|}{ Physical exercise } \\
\hline Yes & 69 & 53 & - & - & - \\
\hline No & 169 & 29 & $2.09(0.88-4.30)$ & $0.988(0.0218,1.770)$ & 0.627 \\
\hline \multicolumn{6}{|c|}{ Previous exposure to any education regarding diet recommendation from healthcare providers } \\
\hline Yes & 79 & 69 & - & - & - \\
\hline No & 191 & 13 & $5.24(3.49-8.37)$ & $8.14(2.27-47.29) *$ & $0.0001^{*}$ \\
\hline
\end{tabular}

Level, * significant at 0.05 level

AOR Adjusted Odds Ratio, COR Crude Odds Ratio, Cl Confidence Interval

of our research. This inconsistency could be explained by the variation in the settings of the study, the difference in socioeconomics, as well as the difference in the types of foods available in the two cities.
There are established studies that examine the association between a low-carbohydrate diet and various cardiovascular risk factors in the past years. Results from a systematic review and meta-analysis of 19 randomized 
clinical trials showed that limiting carbohydrate intake had favorable effects on body weight, BMI, abdominal circumference, systolic blood pressure, diastolic blood pressure, triglyceride level, fasting glucose level, insulin level, HDL cholesterol level, and C-reactive protein level [22]. In addition, another meta-analysis of 13 randomized clinical trials concluded that low-carbohydrate diets in T2DM results in the improvements of glycemic control and triglyceride levels [23]. However, carbohydrate intake is higher in our study participants compared to another source of foods. The average level of carbohydrate intake for the present study participants were more than 5 times a week. This is because rice and potatoes are the staple food and primary dietary source of carbohydrates in South Gondar zone which is the study area. On the other hand, our participants had a low consumption of fruits and vegetables and foods high in omega-3 fats which is also consistent with the eating habits of the general population in Ethiopia. Seasonality of fruits and vegetables and cost could be the reason for low adherence. Although identifying barriers to dietary adherence is a complex problem and no literature has addressed these problems previously in Ethiopia, we have identified these barriers from the reports of participants and from the analysis of multivariate logistic regression. In the present study, $87 \%$ of the study participants have cited lack of knowledge/lack of diet education as the main barriers that hinder adherence to the recommended diet. The analysis of multivariate logistic regression of our study reveals that respondents who had no formal education were more likely to be poorly adherent to dietary recommendations than those who attended higher education. Moreover, poor-adherent to dietary recommendations was observed significantly in those patients who had not received any education about dietary recommendations from health care providers compared with those who had exposure to dietary education. Another important reason reported by $67 \%$ of the study participants did not believe that diet can control blood glucose. This meant that they did not know what or how much to eat, or which foods are recommended for T2DM. Therefore, improving the knowledge of diabetic patients regarding dietary recommendations with a special focus on patients with low educational level is highly important. The second most important reason reported by study participants as a reason for non-adherence to diet recommendations was the cost of the recommended diet. About $78 \%$ of the participants reported that they were unable to afford the cost of the recommended diet as the reason for non-adherence. Moreover, in the present study participants with monthly incomes below $\$ 150$ were poorly adherent to dietary recommendations. Findings of the previous study also have been identified the cost of food as a barrier in non-adherence to dietary recommendation among diabetes patients [9, 24, 25]. The annual increase in the cost of healthy foods might have a negative impact on patients who were from low socioeconomic levels like Ethiopia. Therefore, providing reliable information regarding lists of low-cost healthy foods and foods that can be cheaply cooked at home may also be beneficial for patients to overcome the cost barrier for dietary adherence especially in low-income patients. In the multivariate logistic regression analysis, we have identified that the presence of co-morbidities was associated with increased non-adherence to dietary recommendations. Patients with comorbidity are often on complex medication regimens as well as complex dietary recommendations. Therefore, providing adequate information on the benefit of dietary adherence for patients with diabetes with a special focus on patients with comorbidities is an important approach. Inability to remember the recommended diet, difficulty of adhering to the recommended diet during social or work events and stress were also reported as a reason for $39-57 \%$ of patients. Less than $25 \%$ of patient-reported, lack of appetite for recommended diets and length of time to cook healthy food appears as barriers influencing adherence to recommended dietary foods for T2DM.

\section{Limitation of the study}

This study has limitations that must be considered while interpreting the results. Firstly, self-reported data are subject to bias. There is the risk that subjects may not respond according to their true attitudes or opinions. However, this limitation is lessened by the moderately strong reliable and validated survey instrument employed in this study. Moreover, readers and researchers should be aware that the findings of the present study may not represent the population of the entire country as a source of food and other factors may vary across different geographic areas.

\section{Conclusion}

According to our findings, non-adherence to dietary recommendations among T2DM is high as evidenced by $74.3 \%$ of the study participants reporting non-adherence. Lack of knowledge, diet education, and inability to afford the recommended diet, low monthly income, lack of previous exposure to dietary education and presence of co-morbidities were the most significant barriers responsible for non-adherence. Therefore, health professionals must become proactive in identifying and addressing these barriers and health care decision and policymakers should design effective dietary practice guideline for people with T2DM in areas where these are not available.

\section{Acknowledgements}

The authors acknowledge the support of Debre Tabor General Hospital in facilitating the data collection process. 


\section{Funding}

This Study has not received any fund.

\section{Availability of data and materials}

The data are available from the corresponding author on reasonable request.

\section{Authors' contributions}

AAA involved in conception, study tool development, data analysis, and final write-up and editing and approval of final manuscript. HGT involved in conception, principal supervision and revising the final manuscript, SAT and BAA involved in formal analysis and data collection. YKE and ADG involved in tool development, data curation and write-up of the final manuscript. All authors read and approved the final manuscript.

\section{Ethics approval and consent to participate}

Ethical approval was obtained from the ethical review board of Debre Tabor University and informed oral consent was obtained from each participant.

\section{Consent for publication}

Note applicable.

\section{Competing interests}

The authors declare that they have no competing interests.

\section{Publisher's Note}

Springer Nature remains neutral with regard to jurisdictional claims in published maps and institutional affiliations.

\section{Author details}

'Department of Clinical Pharmacy, School of Pharmacy, College of Medicine and Health Science, University of Gondar, BOX 520 Gondar, PO, Ethiopia. ${ }^{2}$ School of Pharmacy, College of Medicine and Health Science, University of Gondar, Gondar, Ethiopia. ${ }^{3}$ Department of Public Health, College of Health Sciences, Debre Tabor University, Debre Tabor, Ethiopia. ${ }^{4}$ Department of Epidemiology and Biostatics, Institute of Public health College of Medicine and Health Science, University of Gondar, Gondar, Ethiopia. ${ }^{5}$ School of Medicine and Pharmacy, University of New England, Armidale, NSW 2351, Australia.

Received: 19 July 2018 Accepted: 6 November 2018

Published online: 29 November 2018

\section{References}

1. World Health Organization. Global Report on Diabetes. Geneva; 2016. http:// www.who.int/diabetes/global-report/en/.

2. Wild S, Roglic G, Green A, Sicree R, King H. Global prevalence of diabetes: estimates for the year 2000 and projections for 2030. Diabetes care. 2004; 27(5):1047-53

3. Federation, International Diabetes (2015). IDF diabetes atlas (https://www. worldcat.org/oclc/961366911) (Seventh ed). Brussels: International Diabetes Federation. ISBN 9782930229812. OCLC 961366911 (https://www.worldcat. org/oclc/961366911)

4. Association AD. standards of Med Care in diabetes-2017.

5. Association AD. Nutrition recommendations and interventions for diabetes: a position statement of the American Diabetes Association. Diabetes Care. 2008;31(Supplement 1):S61-78

6. Broadbent E, Donkin L, Stroh JC. Illness and treatment perceptions are associated with adherence to medications, diet, and exercise in diabetic patients. Diabetes Care. 2011;34(2):338-40.

7. Resnick HE, Foster GL, Bardsley J, Ratner RE. Achievement of American Diabetes Association clinical practice recommendations among US adults with diabetes, 1999-2002 the National Health and nutrition examination survey. Diabetes Care. 2006;29(3):531-7.

8. Khattab M, Khader Y, Khawaldeh A, Ajlouni K. Factors associated with poor glycemic control among patients with type 2 diabetes. J Diabetes Complicat. 2010;24(2):84-9.

9. Vijan S, Stuart NS, Fitzgerald JT, et al. Barriers to following dietary recommendations in type 2 diabetes. Diabet Med. 2005;22:32-8.

10. Nagelkerk J, Reick K, Meengs L. Perceived barriers and effective strategies to diabetes selfmanagement. J Adv Nurs. 2006;54:151-8.
11. Glasgow RE. A practical model of diabetes management and education Diabetes Care. 1995:18:117-26.

12. Cox DJ, Gonder-Frederick L. Major developments in behavioral diabetes research. J Consult Clin Psychol. 1992:60:628.

13. Ayele K, Tesfa B, Abebe L, Tilahun T, Girma E. Self care behavior among patients with diabetes in Harari, eastern Ethiopia: the health belief model perspective. PLoS One. 2012;7:e35515.

14. Worku A, Abebe SM, Wassie MM. Dietary practice and associated factors among type 2 diabetic patients: a cross sectional hospital based study, Addis Ababa, SpringerPlus 2015;4:15.

15. Amoah AG. Sociodemographic variations in obesity among Ghanaian adults. Public Health Nutr. 2003;6:751-7.

16. Emmanuel OO, Otovwe A. Patterns of adherence to management among patients with type 2 diabetes mellitus in south-south region of Nigeria. J Soc Health Diabetes. 2015:3:115.

17. Asaad G, Sadegian M, Lau R, Xu Y, Soria-Contreras DC, Bell RC, Chan CB. The reliability and validity of the perceived dietary adherence questionnaire for people with type 2 diabetes. Nutrients. 2015 Jul 7;7(7):5484-96.

18. Rivellese AA, Boemi M, Cavalot F, Costagliola L, De Feo P, Miccoli R, Patti L, Trovati M, Vaccaro O, Zavaroni I. Mind.It study group. Dietary habits in type II diabetes mellitus: how is adherence to dietary recommendations? Eur J Clin Nutr. 2008:62:660-4

19. Hankó B, Kázmér M, Kumli P, Hrágyel Z, Samu A, Vincze Z, et al. Selfreported medication and lifestyle adherence in Hungarian patients with type 2 diabetes. Pharm World Sci. 2007;29:58-66.

20. Shultz JA, Sprague MA, Branen $\amalg$. Lambeth S. a comparison of views of individuals with type 2 diabetes mellitus and diabetes educators about barriers to diet and exercise. J Health Commun. 2001;6:99-115.

21. Wing RR, Marcus MD, Epstein LH, Salata R. Type II diabetic subjects lose less weight than their overweight nondiabetic spouses. Diabetes Care. 1987;5636(8):10.

22. Swift CS, Armstrong JE, Beerman KA, Campbell RK, Pond-Smith D. Attitudes and beliefs about exercise among persons with non-insulin-dependent diabetes. Diabetes Educ. 1995;21:533-40.

23. Santos FL, Esteves SS, da Costa Pereira A, Yancy WS Jr, Nunes JP. Systematic review and meta-analysis of clinical trials of the effects of low carbohydrate diets on cardiovascular risk factors. Obes Rev. 2012;13:1048-66.

24. Kirk JK, Graves DE, Craven TE, Lipkin EW, Austin M, Margolis KL. Restrictedcarbohydrate diets in patients with type 2 diabetes: a meta-analysis. J Am Diet Assoc. 2008;108:91-100

25. Glanz K, Basil M, Maibach E, Goldberg E, Snyder D. Why Americans eat what they do: taste, nutrition, cost, convenience, and weight control concerns as influences on food consumption. J Am Diet Assoc. 1998;98:1118-26.

Ready to submit your research? Choose BMC and benefit from:

- fast, convenient online submission

- thorough peer review by experienced researchers in your field

- rapid publication on acceptance

- support for research data, including large and complex data types

- gold Open Access which fosters wider collaboration and increased citations

- maximum visibility for your research: over $100 \mathrm{M}$ website views per year

At $\mathrm{BMC}$, research is always in progress.

Learn more biomedcentral.com/submissions 